\title{
Prolonged successful therapy for hyperinsulinaemic hypoglycaemia after gastric bypass: the pathophysiological role of GLP1 and its response to a somatostatin analogue
}

\author{
K S Myint ${ }^{1,4}$, J R Greenfield ${ }^{1}$, I S Farooqi ${ }^{1}$, E Henning ${ }^{1}$, J J Holst ${ }^{2}$ and N Finer ${ }^{1,3}$ \\ ${ }^{1}$ Department of Endocrinology, Institute of Metabolic Science, Cambridge University NHS Trust, Cambridge CB2 OQQ, UK, ${ }^{2}$ Department of Biomedical \\ Sciences, Novo Nordisk Foundation Centre for Basic Metabolic Research, The Panum Institute, University of Copenhagen, DK-2200 Copenhagen, Denmark, \\ ${ }^{3}$ Department of Medicine, University College London, Vascular Physiology Unit, 34 Great Ormond Street, London WC1N 1EH, UK and ${ }^{4}$ Department of \\ Diabetes and Endocrinology, Norfolk and Norwich University Hospital NHS Trust, Colney Lane, Norwich NR4 7UY, UK
}

(Correspondence should be addressed to K S Myint at Department of Diabetes and Endocrinology, Norfolk and Norwich University Hospital NHS Trust; Email: khinswe.myint@nnuh.nhs.uk)

\begin{abstract}
Background: Spontaneous hyperinsulinaemic hypoglycaemia following gastric bypass surgery (GBS) is increasingly recognised. However, its pathophysiology remains unclear. Some patients require pancreatectomy. Medical therapy with calcium channel blockers, acarbose and diazoxide has been reported to be beneficial but has variable adherence and response.

Method: We demonstrate the role of GLP1, counter-regulatory hormones and the subsequent response of GLP1 to somatostatin analogue therapy in a 42-year-old woman with persistent neuroglycopaenia 6 years after GBS. Plasma GLP1, insulin and glucose were measured for $5 \mathrm{~h}$ on three settings: i) a $75 \mathrm{~g}$ oral glucose tolerance test (OGTT); ii) a standard liquid test meal (LTM); and iii) an OGTT 30 min after a s.c. injection of $100 \mu \mathrm{g}$ octreotide.

Results: In comparison with obese non-diabetic controls, the patient had an elevated fasting and a markedly enhanced GLP1 response during the OGTT, followed by an exaggerated insulin response and a subsequent low glucose level. The GLP1 response to a LTM was similar but greater. Octreotide given prior to the OGTT attenuated both the GLP1 and insulin responses and abolished hypoglycaemia. Octreotide therapy significantly improved the patient's neuroglycopaenic symptoms. The hormone profile was reassessed after 6 months following the LTM preceded by octreotide injection. Peak GLP1 and insulin responses were less pronounced than pretreatment responses and without hypoglycaemia. The patient was treated with lanreotide and had remained symptom-free and euglycaemic for 4 years. Conclusion: An exaggerated incretin response following altered gastrointestinal anatomy was the likely cause of hypoglycaemia in our GBS patient. Somatostatin successfully suppressed this response acutely and in the long term, thereby avoiding pancreatectomy and its sequelae.
\end{abstract}

European Journal of Endocrinology 166 951-955

\section{Introduction}

Bariatric surgery is an effective treatment for severe obesity, often leading to the 'remission' of type 2 diabetes $(1,2)$ and a reduction in cardiovascular events and mortality. Spontaneous hypoglycaemia is an increasingly recognised complication of gastric bypass surgery (GBS) (3) and also gastric banding surgery (4). Various mechanisms have been suggested as the cause of spontaneous persistent hyperinsulinaemic hypoglycaemia (PHH). We describe a reversal of $\mathrm{PHH}$ with octreotide therapy in a patient presenting with this symptom 6 years after GBS.

\section{History}

A 36-year-old woman presented with a history of severe obesity since a teenager. She failed to maintain weight loss after multiple weight interventions, including dietary counselling, low-energy liquid diets, jaw wiring and anti-obesity pharmacotherapy. She developed type 2 diabetes at the age of 36 years and was treated with metformin. Subsequently, she underwent GBS, weighing $165 \mathrm{~kg}$ with a body mass index (BMI) of $71 \mathrm{~kg} / \mathrm{m}^{2}$. Following the surgery, anti-diabetic medication was withdrawn and she remained 'diet controlled' thereafter. At 18 months post-GBS, she required revision surgery for staple disruption and further bypass of a loop of the small intestine was performed. She achieved a steady weight loss over the first 2 years and maintained a 53\% weight loss, achieving a BMI of $32.3 \mathrm{~kg} / \mathrm{m}^{2}$.

At 6 years after the GBS, with a BMI maintained at $37.2 \mathrm{~kg} / \mathrm{m}^{2}$, she reported symptoms suggestive of hypoglycaemia occurring at night and in response to 

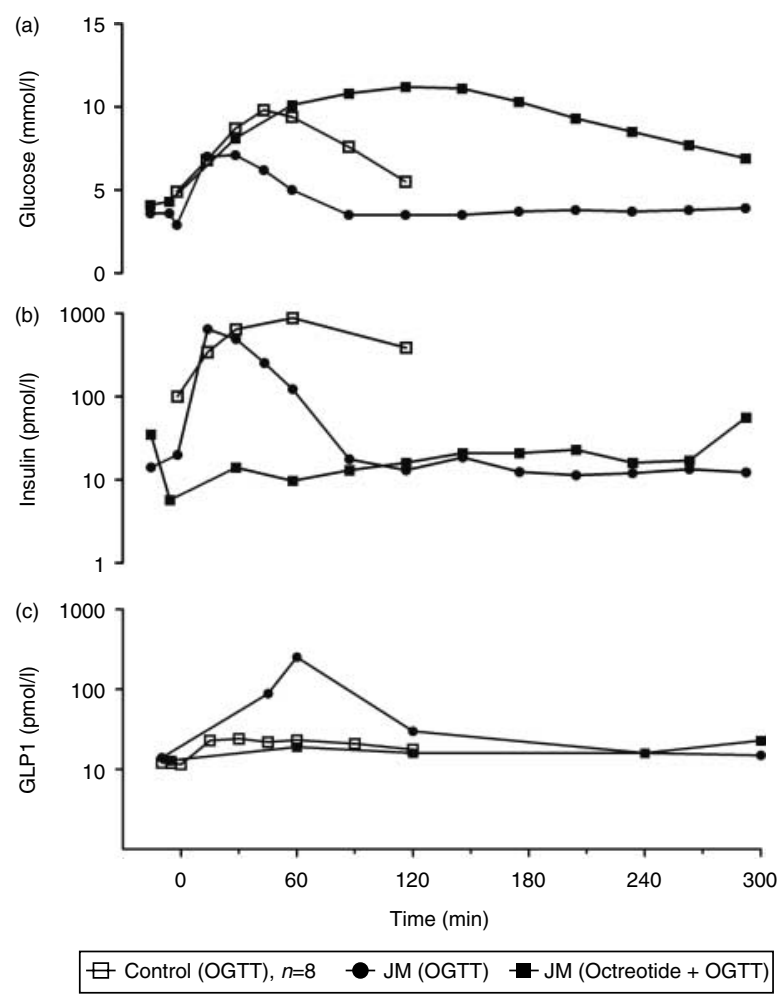

Figure 1 (a) Glucose, (b) insulin and (c) GLP1 response to the OGTT (75 g glucose load) without or with a prior s.c. injection of $100 \mu \mathrm{g}$ octreotide.

meals (postprandial hypoglycaemia). HbA1c was $4.9 \%$. After $66 \mathrm{~h}$ of supervised fasting, she developed symptomatic hypoglycaemia with a plasma glucose concentration of $1.8 \mathrm{mmol} / \mathrm{l}$ and inappropriate levels of insulin (15 pmol/l), proinsulin (2.9 pmol/l) and C-peptide (185 pmol/l). The $32-33$ split proinsulin level was undetectable $(<2 \mathrm{pmol} / \mathrm{l})$. These findings, together with an appropriate ratio of proinsulin to insulin (19\%) below the $>25 \%$ ratio seen in insulinoma patients $(5,6)$, are consistent with those observed in non-insulinoma insulin hypersecretion. The sulphonylurea screen was negative. MRI taken at that time and after 18 months showed no pancreatic abnormality.

\section{Further investigations}

In order to investigate the cause of hypoglycaemia, the incretin GLP1, insulin and glucose were measured in the plasma for $5 \mathrm{~h}$ on three occasions on different days, more than 2 days apart, following: i) a $75 \mathrm{~g}$ oral glucose tolerance test (OGTT); ii) a standard liquid test meal (LTM: $50 \%$ carbohydrate, $30 \%$ fat and $20 \%$ protein to provide $20 \%$ of the estimated energy requirement); and iii) a $75 \mathrm{~g}$ OGTT $30 \mathrm{~min}$ after a s.c. injection of $100 \mu \mathrm{g}$ octreotide, the somatostatin analogue. The GLP1 responses of eight obese nondiabetic control subjects (mean \pm s.D., age $39 \pm 9.8$ years; BMI $34.5 \pm 4.4 \mathrm{~kg} / \mathrm{m}^{2}$ ) following the $75 \mathrm{~g}$ OGTT are also presented as reference data. After 6 months of octreotide treatment, glucose, insulin and GLP1 hormone profiles were analysed throughout the day in relation to meals (estimated total daily energy requirement divided into $20 \%$ breakfast, 35\% lunch, $10 \%$ afternoon snack and 35\% dinner).

\section{Analytical methods}

To determine plasma glucose concentration, blood was collected in a fluoride oxalate tube and assayed on the same day by the glucose oxidase method (YSI 2300; Yellow Springs Instruments, OH, USA). For the insulin assay, plasma was collected in a lithium heparincontaining tube, frozen and stored at $-80{ }^{\circ} \mathrm{C}$ until analysis. Then, insulin was quantified using a commercially available immunoassay (AutoDELFIA Insulin Kit; Perkin Elmer, Wellesley, MA, USA), with an intraassay coefficient of variation (CV) of 3.5-4.5\%. For GLP1, blood was collected into chilled EDTA-coated tubes, which were immediately centrifuged for $7 \mathrm{~min}$ at 3000 r.p.m. Plasma samples were snap-frozen and stored at $-80{ }^{\circ} \mathrm{C}$ until analysis. Plasma GLP1 concentrations were measured by RIAs after extraction of plasma with $70 \%$ ethanol (vol/vol, final concentration). Carboxy-terminal GLP1 immunoreactivity was determined using antiserum 89390 (7), which has an absolute requirement for the intact amidated carboxy-terminus of GLP1 7-36 amide and cross-reacts $<0.01 \%$ with carboxy-terminally truncated fragments and $89 \%$ with GLP1 9-36 amide, the primary metabolite of dipeptidyl peptidase IV-mediated degradation. The sum of the two components (total GLP1 concentrations) reflects the rate of secretion of the L-cell. Sensitivity was below $1 \mathrm{pmol} / \mathrm{l}$, and the intra-assay $\mathrm{CV}$ was below $5 \%$ at $20 \mathrm{pmol} / \mathrm{l}$.

\section{Results}

In the fasting state, the patient had a high basal level of GLP1 compared with the obese controls (22 vs

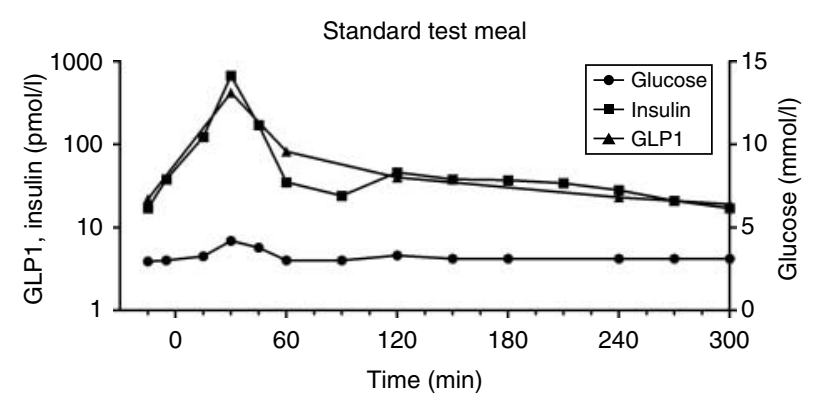

Figure 2 Glucose, insulin and GLP1 response to the standard test meal. 


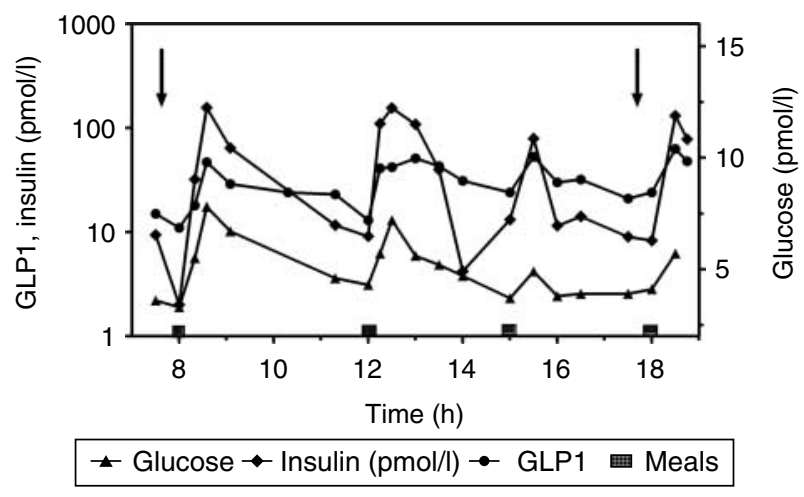

Figure 3 Glucose, insulin and GLP1 levels throughout the day in relation to meals and octreotide injections (arrows).

$12.2 \mathrm{pmol} / \mathrm{l}$; Fig. 1). During the OGTT, a markedly exaggerated rise in GLP1 was observed compared with the control group, with peak levels of 254 vs $23.2 \mathrm{pmol} / \mathrm{l}$ at $60 \mathrm{~min}$. GLP1 levels returned to baseline by $240 \mathrm{~min}$. Insulin levels also increased to nearly double that in the controls (647 vs $341 \mathrm{pmol} / \mathrm{l}$ ) by $15 \mathrm{~min}$. Plasma glucose levels showed a rapid peak at $30 \mathrm{~min}(7 \mathrm{mmol} / \mathrm{l})$ and returned to baseline by $90 \mathrm{~min}$ with the lowest recorded level of $3.5 \mathrm{mmol} / \mathrm{l}$. The GLP1, insulin and glucose responses to the standard test meal are shown in Fig. 2 (peak values: GLP1 418 pmol/l, insulin $669 \mathrm{pmol} / \mathrm{l}$ and glucose $6.9 \mathrm{mmol} / \mathrm{l})$. The GLP1 response was fourfold higher than that found in previously published data of patients who underwent GBS without hypoglycaemia (96 pmol/l) (8). Octreotide injection prior to the OGTT attenuated both GLP1 and insulin peak responses, and not only reversed the low levels of glucose, but also elevated them into a diabetic range ( $2 \mathrm{~h}$ glucose $11.2 \mathrm{mmol} / \mathrm{l}$; Fig. 1 ).

The patient was treated with a low-glycaemic index diet, frequent meals and $20 \mathrm{~g}$ corn starch three times daily with meals and was commenced on $50 \mu \mathrm{g}$ octreotide s.c. twice daily before meals. Her symptoms resolved immediately. HbA1c remained normal (5\%). Subsequently, the dose of octreotide was increased to

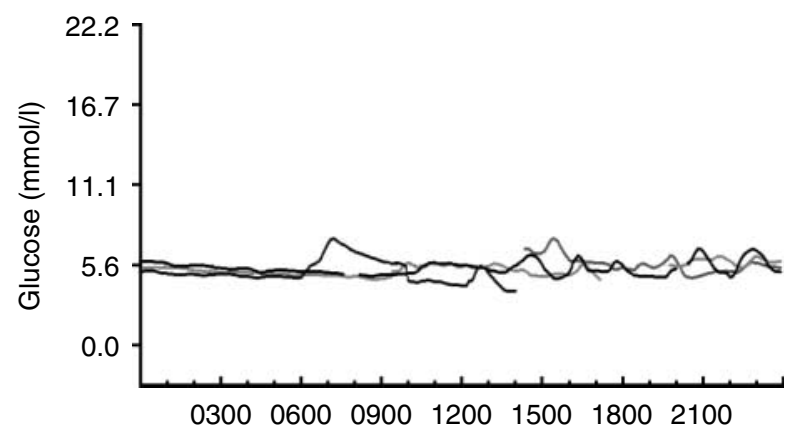

(h)

Figure 4 Continuous glucose monitoring indicating tight glycaemic control (each line represents an individual day).
$100 \mu \mathrm{g}$ twice daily. After 6 months of the treatment, the peak GLP1 and insulin responses to the same breakfast meal administered 6 months previously were much less pronounced (47 vs $418 \mathrm{pmol} / \mathrm{l}$ for GLP1 and $157 \mathrm{vs} 669 \mathrm{pmol} / \mathrm{l}$ for insulin). The hormone and glucose responses throughout the day are shown in Fig. 3. No hypoglycaemia was detected during this study day. Octreotide therapy was changed to the long-acting analogue lanreotide. The patient remained asymptomatic for 4 years. The $72 \mathrm{~h}$ continuous glucose monitoring showed tight glycaemic control with a mean glucose level of 5.3 (range 3.7-7.4) mmol/l (Fig. 4). HbA1c measured at 3-6 monthly intervals had remained between 4.8 and $5.1 \%$. On two occasions due to problems with accessing lanreotide, the patient was without treatment for 2-3 weeks during which time she reported a recurrence of meal-related hypoglycaemia and reported capillary blood glucose levels below $3.5 \mathrm{mmol} / \mathrm{l}$ (lowest $2.9 \mathrm{mmol} / \mathrm{l}$ ).

\section{Discussion}

Sweating, palpitations and fainting episodes, sometimes associated with severe neuroglycopaenia and its sequelae, following GBS are traditionally attributed to the dumping syndrome, a well-recognised complication of this procedure (9).'Early dumping' usually occurs 30-60 min after meals and is thought to be caused by the rapid entry of ingested food into the small bowel causing osmotic shift and hypovolaemia. 'Late dumping' typically occurs $1-3 \mathrm{~h}$ after a meal; it is postulated that this is due to hypoglycaemia from rapid absorption of glucose and overactivation of the incretin axis, leading to inappropriate hyperinsulinaemia. Elevated GLP1 levels have been implicated as a cause of this inappropriate insulin response in patients who have undergone partial or total gastrectomy $(10,11)$.

The improvement in diabetes following GBS is thought to result from decreased insulin resistance associated with caloric restriction and weight loss and enhanced insulin secretion through an altered enteroinsular axis $(12,13,14)$, and even possibly through the activation of dormant $\beta$-cells (15). Reports of PHH following GBS first appeared in $2004(3,16)$. An insulinoma was diagnosed in one patient who underwent pancreatectomy achieving cure. In 2005, Service et al. (3) described nesidioblastosis in six cases of PHH following GBS. All patients received distal pancreatectomy with subsequent cure or improvement of hypoglycaemia. A link between GLP1 hypersecretion causing pancreatic $\beta$-cell growth, hyperfunction and nesidioblastosis was suggested. Subsequently, more cases of nesidioblastosis following GBS have been reported and all received pancreatectomy to control their symptoms $(17,18,19)$.

$\mathrm{PHH}$ without evidence of insulinoma is rare in adults. Histologically, these patients have islet enlargement, 
hypertrophic $\beta$-cells with enlarged hyperchromatic nuclei and abundant clear cytoplasm $(17,20)$. The detailed histology of the six cases reported by Service et al. was reanalysed subsequently using a different control group from autopsy specimens $(7,17)$. In contrast to the previous report, there was no evidence of increased $\beta$-cell formation estimated by the islet cell fractional area (which was not performed in the original study) or decreased $\beta$-cell loss in patients post-GBS.

\section{Incretin hormones and the pancreatic insular axis}

Incretin are hormones released from the gut in response to nutrient ingestion, enhancing glucose-stimulated insulin secretion (21). The two principal peptides with incretin-like activity are glucose-dependent insulinotropic peptide (GIP) and GLP1. GLP1 is secreted by the L-cells in the distal ileum in response to nutrient delivery. In addition to its glucose-dependent insulinotropic effect, GLP1 decelerates gastric emptying and suppresses glucagon secretion (22). Impaired postprandial GLP1 secretion has been demonstrated in the obese (23) and in patients with type 2 diabetes $(24,25,26)$. Patients with impaired glucose tolerance have GLP1 responses intermediate between normal and type 2 diabetic patients (27). Administration of either exogenous GLP1 or a potent GLP1 agonist (exendin 4) has been shown to suppress energy intake in humans $(24,28)$. Exendin 4 and GLP1 analogues are now available as therapeutic agents for type 2 diabetes.

In morbidly obese patients who have undergone GBS, the GLP1 response to a meal is markedly increased compared with obese control patients without surgery $(8,29)$. Our patient had an even higher GLP1 peak at $418 \mathrm{pmol} / \mathrm{l}$ (12-fold; Fig. 2). An exaggerated GLP1 response (up to 12 times higher than the controls) is also found in non-obese patients who undergo total gastrectomy for indications other than morbid obesity (11), contributing to the late dumping syndrome. Therefore, it appears that the presence of glucose distal to the stomach is necessary to stimulate GLP1 release.

Others have hypothesised that rapid digestion and absorption of carbohydrate is an important contributing feature to PHH after GBS (4). They have demonstrated exaggerated plasma insulin responses and hypoglycaemia following high-carbohydrate mixed meals, compared with little change in plasma insulin and no hypoglycaemia after low-carbohydrate test meals. In the GBS, as part of the proximal jejunum is bypassed, the rise of GIP is less pronounced than GLP1 (30); GIP is less likely to be responsible for excess insulin secretion. McLaughlin et al. (31) recently reported a case of PHH following GBS in which delivering food via a gastrostomy tube reduced the incretin response compared with orally and abolished hypoglycaemia. Others (32) have reported that surgical restoration of gastric restriction to slow down the release of glucose into the intestine improved hypoglycaemia. However, in a recent study, the exaggerated effect of GLP1 on postprandial insulin secretion in surgical subjects was not significantly different from those with and without recurrent hypoglycaemia (14).

In this case, we demonstrated an exaggerated peak GLP1 response during an OGTT and test meal, which was much greater than that observed in matched obese control subjects and post-GBS patients without a history of hypoglycaemia (8). We suggest that this markedly increased incretin effect is the likely cause of postprandial hypoglycaemia. This release of GLP1 after glucose challenge was clearly inhibited by prior octreotide injection, thereby preventing hypoglycaemia. This suggests that the rapid transit of food into the intestine (perhaps exacerbated by the revised surgery) may partly explain the surge of GLP1 that we observed. Octreotide blocks SSR-2, -4 and -5 . These receptors are present in the intestine where the L-cells are located. Promisingly, the effect of octreotide and, latterly, lanreotide has been maintained for 4 years, avoiding the need for pancreatectomy and its serious potential complications.

In conclusion, we report a case of successful reversal of PHH with octreotide 6 years following GBS. In this case report, the response of the patient with $\mathrm{PHH}$ postGBS to somatostatin treatment suggests that a trial of octreotide therapy should be considered in patients with this condition, particularly if no lesion is identified on pancreatic imaging. Our case demonstrates that treatment with octreotide may obviate the need for pancreatectomy in selected cases.

\section{Declaration of interest}

The authors declare that there is no conflict of interest that could be perceived as prejudicing the impartiality of the research reported.

\section{Funding}

This research did not receive any specific grant from any funding agency in the public, commercial or not-for-profit sector.

\section{Acknowledgements}

We are grateful to Dr S Aylwin and Dr C LeRoux for their discussions about this patient, and the nursing staff at the Wellcome Trust Clinical Research Facility.

\section{References}

1 Pories WJ, Swanson MS, MacDonald KG, Long SB, Morris PG, Brown BM, Barakat HA, de Ramon RA, Israel GDolezal JM et al. Who would have thought it? An operation proves to be the most effective therapy for adult-onset diabetes mellitus. Annals of Surgery 1995222 339-350. (doi:10.1097/00000658-19950900000011)

2 Buchwald H, Avidor Y, Braunwald E, Jensen MD, Pories W, Fahrbach K \& Schoelles K. Bariatric surgery: a systematic review and meta-analysis. Journal of the American Medical Association 2004292 1724-1737. (doi:10.1001/jama.292.14.1724) 
3 Service GJ, Thompson GB, Service FJ, Andrews JC, CollazoClavell ML \& Lloyd RV. Hyperinsulinemic hypoglycemia with nesidioblastosis after gastric-bypass surgery. New England Journal of Medicine 2005353 249-254. (doi:10.1056/NEJMoa043690)

4 Scavini M, Pontiroli AE \& Folli F. Asymptomatic hyperinsulinemic hypoglycemia after gastric banding. New England Journal of Medicine 2005353 2822-2823. (doi:10.1056/NEJMc052356)

5 Vezzosi D, Bennet A, Fauvel J \& Caron P. Insulin, C-peptide and proinsulin for the biochemical diagnosis of hypoglycaemia related to endogenous hyperinsulinism. European Journal of Endocrinology 2007157 75-83. (doi:10.1530/EJE-07-0109)

6 Hampton SM, Beyzavi K, Teale D \& Marks V. A direct assay for proinsulin in plasma and its applications in hypoglycaemia. Clinical Endocrinology $1988 \quad 29$ 9-16. (doi:10.1111/j.13652265.1988.tb00244.x)

7 Meier JJ, Butler AE, Galasso R \& Butler PC. Hyperinsulinemic hypoglycemia after gastric bypass surgery is not accompanied by islet hyperplasia or increased beta-cell turnover. Diabetes Care 200629 1554-1559. (doi:10.2337/dc06-0392)

8 Korner J, Bessler M, Inabnet W, Taveras C \& Holst JJ. Exaggerated glucagon-like peptide- 1 and blunted glucose-dependent insulinotropic peptide secretion are associated with Roux-en-Y gastric bypass but not adjustable gastric banding. Surgery for Obesity and Related Diseases 20073 597-601. (doi:10.1016/j.soard.2007.08. 004)

9 Patti ME \& Goldfine AB. Hypoglycaemia following gastric bypass surgery - diabetes remission in the extreme? Diabetologia 201053 2276-2279. (doi:10.1007/s00125-010-1884-8)

10 Toft-Nielsen M, Madsbad S \& Holst JJ. Exaggerated secretion of glucagon-like peptide-1 (GLP-1) could cause reactive hypoglycaemia. Diabetologia $1998 \quad 41$ 1180-1186. (doi:10.1007) s001250051049)

11 Miholic J, Orskov C, Holst JJ, Kotzerke J \& Meyer HJ. Emptying of the gastric substitute, glucagon-like peptide-1 (GLP-1), and reactive hypoglycemia after total gastrectomy. Digestive Diseases and Sciences 199136 1361-1370. (doi:10.1007/BF01296800)

12 Gumbs AA, Modlin IM \& Ballantyne GH. Changes in insulin resistance following bariatric surgery: role of caloric restriction and weight loss. Obesity Surgery 200515 462-473. (doi:10. $1381 / 0960892053723367$ )

13 Mason EE. The mechanisms of surgical treatment of type 2 diabetes. Obesity Surgery 200515 459-461. (doi:10.1381/ 0960892053723330)

14 Salehi M, Prigeon RL \& D’Alessio DA. Gastric bypass surgery enhances glucagon-like peptide 1-stimulated postprandial insulin secretion in humans. Diabetes 201160 2308-2314. (doi:10.2337/db11-0203)

15 Olsson R \& Carlsson PO. A low-oxygenated subpopulation of pancreatic islets constitutes a functional reserve of endocrine cells. Diabetes 201160 2068-2075. (doi:10.2337/db09-0877)

16 Zagury L, Moreira RO, Guedes EP, Coutinho WF \& Appolinario JC. Insulinoma misdiagnosed as dumping syndrome after bariatric surgery. Obesity Surgery 200414 120-123. (doi:10.1381/ 096089204772787419)

17 Clancy TE, Moore FD Jr \& Zinner MJ. Post-gastric bypass hyperinsulinism with nesidioblastosis: subtotal or total pancreatectomy may be needed to prevent recurrent hypoglycemia. Journal of Gastrointestinal Surgery $2006 \quad 10$ 1116-1119. (doi:10.1016/j.gassur.2006.04.008)

18 Patti ME, McMahon G, Mun EC, Bitton A, Holst JJ, Goldsmith J, Hanto DW, Callery M, Arky R, Nose V, Bonner-Weir S \& Goldfine AB. Severe hypoglycaemia post-gastric bypass requiring partial pancreatectomy: evidence for inappropriate insulin secretion and pancreatic islet hyperplasia. Diabetologia $2005 \mathbf{4 8}$ 2236-2240. (doi:10.1007/s00125-005-1933-x)
19 Alvarez GC, Faria EN, Beck M, Girardon DT \& Machado AC. Laparoscopic spleen-preserving distal pancreatectomy as treatment for nesidioblastosis after gastric bypass surgery. Obesity Surgery 200717 550-552. (doi:10.1007/s11695-007-9096-0)

20 Anlauf M, Wieben D, Perren A, Sipos B, Komminoth P, Raffel A, Kruse ML, Fottner C, Knoefel WT, Mönig H, Heitz PU \& Klöppel G. Persistent hyperinsulinemic hypoglycemia in 15 adults with diffuse nesidioblastosis: diagnostic criteria, incidence, and characterization of beta-cell changes. American Journal of Surgical Pathology 200529 524-533. (doi:10.1097/01.pas. 0000151617.14598.ae)

21 Unger RH \& Eisentraut AM. Entero-insular axis. Archives of Internal Medicine 1969123 261-266. (doi:10.1001/archinte. 1969.00300130043007)

22 Meier JJ \& Nauck MA. Glucagon-like peptide 1 (GLP-1) in biology and pathology. Diabetes/Metabolism Research and Reviews 200521 91-117. (doi:10.1002/dmrr.538)

23 Ranganath LR, Beety JM, Morgan LM, Wright JW, Howland R \& Marks V. Attenuated GLP-1 secretion in obesity: cause or consequence? Gut 199638 916-919. (doi:10.1136/gut.38.6. 916)

24 Drucker DJ. Minireview: the glucagon-like peptides. Endocrinology 2001142 521-527. (doi:10.1210/en.142.2.521)

25 Toft-Nielsen MB, Madsbad S \& Holst JJ. Determinants of the effectiveness of glucagon-like peptide-1 in type 2 diabetes. Journal of Clinical Endocrinology and Metabolism $2001 \quad 86$ 3853-3860. (doi:10.1210/jc.86.8.3853)

26 Greenfield JR, Farooqi IS, Keogh JM, Henning E, Habib AM, Blackwood A, Reimann F, Holst JJ \& Gribble FM. Oral glutamine increases circulating glucagon-like peptide 1, glucagon, and insulin concentrations in lean, obese, and type 2 diabetic subjects. American Journal of Clinical Nutrition 200989 106-113. (doi:10. 3945/ajcn.2008.26362)

27 Toft-Nielsen MB, Damholt MB, Madsbad S, Hilsted LM, Hughes TE, Michelsen BK \& Holst JJ. Determinants of the impaired secretion of glucagon-like peptide- 1 in type 2 diabetic patients. Journal of Clinical Endocrinology and Metabolism 200186 3717-3723. (doi:10.1210/jc.86.8.3717)

28 Holst JJ. The physiology of glucagon-like peptide 1. Physiological Reviews 200787 1409-1439. (doi:10.1152/physrev.00034. 2006)

29 Borg CM, le Roux CW, Ghatei MA, Bloom SR, Patel AG \& Aylwin SJ. Progressive rise in gut hormone levels after Roux-en-Y gastric bypass suggests gut adaptation and explains altered satiety. British Journal of Surgery 200693 210-215. (doi:10.1002/bjs. 5227)

30 Goldfine AB, Mun EC, Devine E, Bernier R, Baz-Hecht M, Jones DB, Schneider BE, Holst JJ \& Patti ME. Patients with neuroglycopenia after gastric bypass surgery have exaggerated incretin and insulin secretory responses to a mixed meal. Journal of Clinical Endocrinology and Metabolism 200792 4678-4685. (doi:10.1210/jc. 2007-0918)

31 McLaughlin T, Peck M, Holst J \& Deacon C. Reversible hyperinsulinemic hypoglycemia after gastric bypass: a consequence of altered nutrient delivery. Journal of Clinical Endocrinology and Metabolism 201095 1851-1855. (doi:10.1210/jc.20091628)

32 Z'graggen K, Guweidhi A, Steffen R, Potoczna N, Biral R, Walther F, Komminoth P \& Horber F. Severe recurrent hypoglycemia after gastric bypass surgery. Obesity Surgery 200818 981-988. (doi:10.1007/s11695-008-9480-4)

Received 12 December 2011

Revised version received 26 February 2012

Accepted 9 March 2012 